\title{
HOW DOES BODY SYMMETRY INFLUENCE STANDING BALANCE?
}

\author{
Ana Kašček Bučinel ${ }^{1}$, Matej Supej ${ }^{1}$, Nicola Petrone ${ }^{2}$, and Ivan Čuk ${ }^{1}$ \\ ${ }^{1}$ Faculty of Sports, University of Ljubljana, Slovenia \\ ${ }^{2}$ Department of Industrial Engineering, University of Padova, Italy
}

\begin{abstract}
:
The aim of the study was to determine whether maintaining the standstill balance position was influenced by athlete's asymmetric morphological characteristics. Thirty-two male healthy sports students participated in this study (age 19.8 \pm 1.4 years, body height $182.9 \pm 6.8 \mathrm{~cm}$, body weight $79.1 \pm 8.1 \mathrm{~kg}$ ). Morphological characteristics are represented with the differences between the left and the right body side of the forearm girth, upper arm girth, calf girth, thigh girth, long shoulder height, leg lean mass and arm lean mass. The standstill balance result was calculated as a result of factor scores for 9 measurements of 30 seconds (3 measurements of simple standstill, 3 measurements of blinded standstill, and 3 measurements of deafened standstill) collected from the pressure insole system and the difference in ground reaction force (GRF) between the left and the right leg. The results show that the asymmetric leg load in maintaining standstill balance depends on the side differences in the thigh and upper arm girth. The greater difference in the thigh girth in favour of the left side resulted in bigger GRF on the right leg compared to the left leg, and the greater difference in the upper arm girth in favour of the left side resulted in bigger GRF on the left leg. To avoid the one body side overload, it is essential that all sports activities are performed bilaterally.
\end{abstract}

Key words: $3 D$ scan, body asymmetry, In Body, postural stability, pressure insole

\section{Introduction}

Horak (1987) defines balance as "the ability to maintain equilibrium in a gravitational field by keeping or returning the centre of body mass over its base of support" (p. 1881). Winter (1995) claims that balance is a general term. It describes the dynamics of body posture, which is related to the inertial forces taking effect on the body and the inertial characteristics of individual body segments.

Sensory information for postural control comes from the somatosensory system, the vestibular system and vision. The somatosensory system includes muscle proprioception, joints and cutaneous afferents (Shumway-Cook \& Horak, 1986). The preferred sensory input for the control of balance for healthy adults is somatosensory information from the feet in contact with the support surface (Shumway-Cook \& Horak, 1986). When standing upright and when the vertical projection of the centre-of-mass to the ground does not cross borders of the support base, the body uses two main strategies to compensate for the induced unbalance. In the front-to-back plane, stability can be maintained by the ankle with the classic stretch reflex and when the body moves backwards, the m.gastrocnemii and hamstrings have the most common response. The central nervous system (CNS) first stabilizes the joint closer to the disturbance - the ankle, and then follows the stabilization of increasingly more distant joints - the knee, hip, and spine. Such maintenance of balanced position is called the "ankle strategy". When it comes to balance disturbances in the latero-medial plane, the body responds with the "hip strategy". This induces more complex developments, particularly in the hips and trunk (Winter, 1995).

Postural stability and balance represent a key function for performing day-to-day tasks. Aging and a number of pathologies often increase the amount of postural sways, which may lead to falls (Maffiuletti, et al., 2005). Falls frequently lead to injuries or fatalities, particularly among older adults. Approximately $30 \%$ of people over 65 years, living in the community, fall each year (Gillespie, et al., 2012; Stevens, Corso, Finkelstein, \& Miller, 2006), but research suggests that falls and fall injuries are also common among middle-aged adults (Talbot, Musiol, Witham, \& Metter, 2005). 
Balance is an important ability also in majority of sports. The authors claim that intense sports training causes increases of muscular girth and epiphysis width as well as the reduction of body fat (Krawczyk, Sklad, \& Majle, 1995), but muscle power, body weight, body mass index (BMI) and body fat have an important influence on maintaining body balance position (Carter, et al., 2002; Goulding, 2003; Maciaszek, 2006; Maureen \& Thornby, 1995). Smith, Weiss and Lehmkuhl (1997) describe that the level of body stability depends on four distinct factors: body weight, height of the centre of gravity, size of the support base, and location of the gravity projection within this support base. According to Oliveira, Imbiriba, and Garcia (2000), dislocation velocity and the centre of pressure (COP) area are related to anthropometric data of individuals.

Many research studies have proved that in sports we could recognize the difference between the right and the left side of the body, which is defined as morphological asymmetry (Auerbach \& Ruff, 2006). Krawczyk, Skład, Majle, and Jackiewicz (1998) claimed that the right-left differences in anthropometric measurements were more recognizable in the athletes of sports representing asymmetric movements than in the athletes of sports employing symmetric movements.

In a previous study it was found out that the body asymmetry was significant in sports which had typically unilateral muscle loading, for example handball, tennis, javelin throw, etc. (Šarabon, Košak, Fajon, \& Drakslar, 2005). Furthermore, Krawczyk et al. (1998) observed 134 athletes aged 21-32 years, during many different asymmetric movement sports like tennis, canoeing, kayaking and boxing in terms of the right-left differences in morphological parameters (forearm girth, upper arm girth, elbow width). In another study (Kruger, Ridder, Underhay, \& Grobbelaar, 2005), the authors noticed that 19 elite international male javelin throwers (age 26.4 4.4 years) developed upper body morphological asymmetry. Thirteen out of fourteen variables had larger values on the dominant body side, especially for triceps skinfold (5.9\%), half-chest girth (4.9\%), forearm girth (3.9\%), and biceps skinfold (2.5\%). Absaljamov, Zorin, and Koz (1976) claimed that because of a higher mechanical load it was obvious that hurdlers, high jumpers and pole vaulters exhibited higher muscle contractility in their swing leg than in the take-off leg. Some authors (Čuk, et al., 2012a) observed that the skittleplayers had a significantly asymmetric body and asymmetric muscular efficiency. Additionally, in the research by Maughan, Abel, Watson, and Weir (1986), the results showed a greater proportion of muscle and smaller proportion of fat in the dominant arm than in the opposite limb in tennis players.
However, it is interesting that body asymmetry is significant not only in sports, which have typically unilateral muscle loading, but also in sports where we expect body symmetry. In the study by Čuk, Pajek, Jakše, Pajek, and Peček (2012b) with a sample of 40 top-level gymnasts (average age of 23 years), who participated in the 2000 World Cup Competition in Ljubljana, the researchers found significant differences in elbow diameter, circumference of the forearm, skinfold thickness of triceps and brachii biceps. Šarabon et al. (2005) claimed that repeated unilateral burden on healthy locomotor system might lead to functional abnormalities of human posture. The deviation from a perfect body symmetry is caused by a lack of development accuracy. Cronin (2010) also claimed that asymmetries between the lower limbs were thought to increase the risk of injury during athletic movements and compromise performance. Systematic sports training causes the side difference in body posture due to the difference in muscular-ligament apparatus between the left and right side of the torso, which is the result of asymmetric body muscle development (Šarabon, et al., 2005).

However, according to our knowledge, there is no research where balance abilities would be related to body morphological (a)symmetries. Therefore, the aim of the study was to investigate if the morphological characteristics, especially bilateral asymmetry, had influence on human balance position. The hypothesis to be tested is that morphological bilateral asymmetries have impact on differences in proportion of the left and the right leg ground reaction force (GRF) in standstill balance.

\section{Methods}

Participants. Thirty-two male sports students registered in the academic 2015/2016 year at the Faculty of Sports participated in this study. Their average age was $19.8 \pm 1.4$ years, their body height $182.9 \pm 6.8 \mathrm{~cm}$ and their body weight was $79.1 \pm 8.1$ $\mathrm{kg}$. Subjects had no medical conditions, none of them was a high-performance athlete, and their sports orientations were random. The institutional ethics committee approved the study and it was performed in accordance with the Declaration of Helsinki. Informed consent to study participation was obtained from all participants.

Measures and procedures. Measurements were conducted in two stages. In the first part, the morphological measurements were collected. For morphological measurements the InBody 720 system and 3D body scanner were used. The InBody 720 bioimpedance measures each individual with a high repeatability (Biospace, 2008) and its measurement methods are reliable and valid. Gibson, Holmes, Desautels, Edmonds, and Nuudi (2008) proved the validity of the device InBody 720 in the 
study that showed a high correlation with DEXA and underwater weighing. The 3D body scanner (NX-16 [TC $]^{2}$, Cary, North Carolina) scans the whole body and produces a true-to-scale 3D body model. A multi-scan option with three consecutive scans was used to obtain the data. The three consecutive scans took 24 seconds and subjects were told to keep still as much as possible. In addition, findings of the research by Zancanaro, Milanese, Lovato, Sandri, and Giachetti (2015) showed the reliability of the 3D scanner anthropometry performed by differently skilled anthropometrists.

The morphological variables were also measured. From the InBody 720 data the leg lean mass and arm lean mass data were taken and from the 3D body scanner (according to ISO 20685:2010 norms) the data were taken on girths (forearm, upper arm, calf, and thigh), and on long shoulder height (a vertical line from the shoulder point to the floor; the value is the height of the shoulder point above the floor).

The second part of measurements consisted of the body balance maintenance tests. All participants used two in-shoe insoles with pressure sensors (PedarX, Novel GmbH, Munich, Germany), feet size, but they were not wearing shoes; the insoles were between two socks, because shoes might change the ankle balance. The measurement system PedarX proved to be accurate and reliable and measurements were valid (Boyd, Bontrager, Mulroy, \& Perry, 1997). The PedarX system was fastened around subject's waist in the middle of the back with the elastic belt, thus it was not an obstacle for the subject, and additionally it did not enforce asymmetric load on their feet. The total weight of PedarX system is $0.400 \mathrm{~kg}$. Data are wirelessly transferred from the system to the computer with a built-in bluetooth module.

Participants executed three repetitions of each of the three types of standstill balance measurements. Each repetition lasted 30 seconds. The first type was a simple standstill. All subjects were standing with their feet together, hands close to their bodies and they were looking forward. The second measurement type was a blinded standstill where they were wearing dimmed glasses through which nothing could be seen. The third measurement type was a deafened standstill where they were wearing protection earmuffs ( $3 \mathrm{M}^{\mathrm{TM}}$ PELTOR ${ }^{\mathrm{TM}}$ Optime ${ }^{\mathrm{TM}}$ II) with attention rating of 31 decibels (as shown in Figure 1). All measurements were randomly done and the participants had $15 \mathrm{~s}$ to rest between each one.

The PedarX system collected results for gravity force on the left and the right foot separately. The scanning rate was $50 \mathrm{~Hz}$ and time per frame was $0.02 \mathrm{~s}$. Force $[\mathrm{N}]$ results of gravity force on each foot were received every $0.02 \mathrm{~s}$. The results revealed there were differences in force load between the

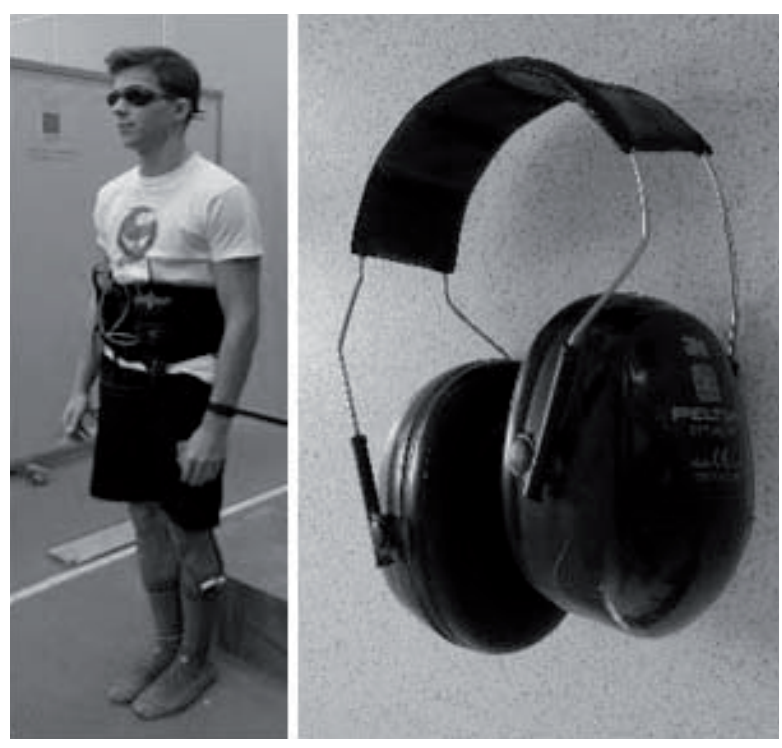

Figure 1. Blinded standstill and earmuffs.

legs. We calculated the difference in force between the legs every $0.02 \mathrm{~s}$ as well as the average difference in the whole measurement. We always calculated the left leg gravity force minus the right leg gravity force. If the forces on both legs were the same, balance was perfect.

For analysis, we used the bilateral difference in every specific morphological characteristic. Our anthropometrical variables were bilateral differences in: leg lean mass (Diff. leg lean mass), arm lean mass (Diff. arm lean mass), long shoulder height (Diff. long shoulder height), thigh girth (Diff. thigh girth), upper arm girth (Diff. upper arm girth), calf girth (Diff. calf girth) and forearm girth (Diff. forearm girth).

Statistical analysis. All data were analysed by Microsoft Excel 2010 and statistical package SPSS 22.0. First, Kolmogorov-Smirnov test was used to verify normal distribution of the variables. Pairwise $t$-test was used to establish differences between the left and the right side. Additionally, tests of reliability were done (factor analysis, Cronbach's alpha).

Balance was evaluated in two steps. In the first step, we did factor analysis (principal components) for each of the standstill types from three variables of the difference in pressure between the legs (items one to three). For the first factor, we calculated factor scores (regression model). In the second step we continued with the first factor scores for each type of standstill (calculated by a regression model), did a factor analysis (principal components) and calculated the factor scores for the first factor - this was used as the depended variable in regression.

Regression analysis (method Enter) for the dependent difference in gravity force (left/right leg) and side difference in morphological characteristics (left/right side of the body) were calculated. All statistical analyses were tested at $\mathrm{p}<.05$. 


\section{Results}

Kolmogorov-Smirnov test showed that all variables were distributed normally except for the bilateral difference in calf and forearm girths. The dependent variable was normally distributed and therefore further multivariate analysis was allowed. The overall reliability (Cronbach's alpha) for the differences in gravity force between the legs during the simple standstill, blinded standstill and deafened standstill was .917, which was in accordance with Tyson et al. (2006) and Chien et al. (2007).
Figure 2 there is an example of one subject's left and right gravity force and the difference between them. We can clearly identify the differences between the legs. In this example, the difference in COP between the left and the right leg is $112.31 \pm 22.34 \mathrm{~N}$; however, among the tested subjects the values were individually determined.

The results of regression analysis for the dependent "factor standstill" and the independent anthropometrical variables were significant at $\mathrm{p}<.05$.

Table 1. Descriptive statistic

\begin{tabular}{lcccccc}
\hline & Mean & Std. deviation & $\mathrm{K}-\mathrm{S}$ & Maximum & Minimum & $\mathrm{P}_{\text {t-test }}$ \\
\hline Diff. calf girth [cm] & .05 & .51 & $\mathrm{not}$ & .90 & -1.60 & .59 \\
Diff. upper arm girth [cm] & -.33 & 1.12 & $\mathrm{n}$ & 2.10 & -2.70 & .11 \\
Diff. forearm girth [cm] & -.48 & .81 & $\mathrm{not}$ & 2.50 & -1.60 & .00 \\
Diff. thigh girth [cm] & .34 & 2.34 & $\mathrm{n}$ & 5.60 & -4.90 & .41 \\
Diff. long shoulder height [cm] & -1.17 & 1.74 & $\mathrm{n}$ & 3.50 & -3.70 & .00 \\
Diff. arm lean mass [kg] & -.04 & .12 & $\mathrm{n}$ & .17 & -.39 & .06 \\
Diff. leg lean mass [kg] & -.04 & .13 & $\mathrm{n}$ & .39 & -.22 & .11 \\
Diff. standstill 1 [N] & 17.90 & 75.62 & $\mathrm{n}$ & 139.09 & -137.32 & .19 \\
Diff. standstill 2 [N] & 15.70 & 64.93 & $\mathrm{n}$ & 124.74 & -188.60 & .18 \\
Diff. standstill 3 [N] & 17.78 & 52.78 & $\mathrm{n}$ & 121.39 & -83.28 & .07 \\
Diff. deafened standstill 1 [N] & 16.53 & 73.61 & $\mathrm{n}$ & 142.73 & -180.50 & .21 \\
Diff. deafened standstill 2 [N] & 21.76 & 67.22 & $\mathrm{n}$ & 193.67 & -84.22 & .08 \\
Diff. deafened standstill 3 [N] & 16.99 & 55.37 & $\mathrm{n}$ & 145.80 & -82.38 & .09 \\
Diff. blinded standstill 1 [N] & 5.59 & 69.91 & $\mathrm{n}$ & 114.40 & -142.77 & .65 \\
Diff. blinded standstill 2 [N] & 4.22 & 55.54 & $\mathrm{n}$ & 121.65 & -95.78 & .67 \\
Diff. blinded standstill 3 [N] & 19.74 & 64.11 & $\mathrm{n}$ & 157.23 & -160.26 & .09 \\
Factor standstill & .00 & 1.00 & $\mathrm{n}$ & 1.97 & -1.98 & \\
\hline
\end{tabular}

Note. $\mathrm{n}$ - normal distribution, not - not normal distribution.

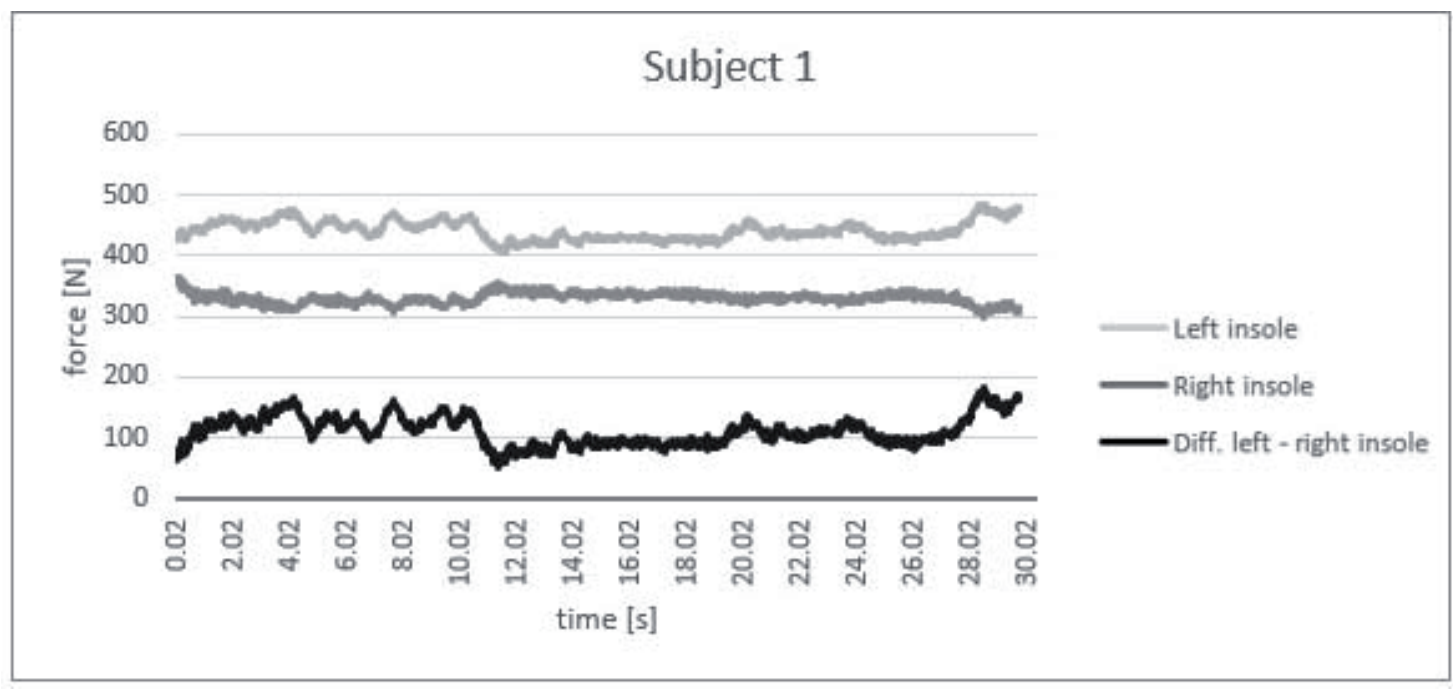

Figure 2. Example of ground reaction force for the right and the left leg and the difference between them while standing still. 
Table 2. Results of factor analyses

\begin{tabular}{|c|c|c|c|c|c|}
\hline & \multirow{2}{*}{$\begin{array}{c}\begin{array}{c}\text { Commun- } \\
\text { alities }\end{array} \\
\text { Extraction }\end{array}$} & \multicolumn{2}{|c|}{$\begin{array}{l}\text { Total variance explained } \\
\text { initial eigenvalues }\end{array}$} & \multirow[t]{2}{*}{$\begin{array}{l}\text { Component } \\
\text { matrix }\end{array}$} & \multirow[t]{2}{*}{$\begin{array}{l}\text { Cronbach's } \\
\text { alpha }\end{array}$} \\
\hline & & Total & Cumulative $\%$ & & \\
\hline 1. Diff. standstill 1 & .72 & 2.13 & 70.99 & .85 & .788 \\
\hline 2. Diff. standstill 2 & .79 & .55 & 89.21 & .89 & \\
\hline 3. Diff. standstill 3 & .63 & .32 & 100.00 & .79 & \\
\hline 1. Diff. deafened standstill 1 & .76 & 2.41 & 80.18 & .87 & .868 \\
\hline 2. Diff. deafened standstill 2 & .84 & .36 & 92.09 & .91 & \\
\hline 3. Diff. deafened standstill 3 & .81 & .24 & 100.00 & .90 & \\
\hline 1. Diff. blinded standstill 1 & .76 & 1.73 & 57.60 & .87 & .627 \\
\hline 2. Diff. blinded standstill 2 & .54 & .85 & 85.76 & .74 & \\
\hline 3. Diff. blinded standstill 3 & .42 & .43 & 100.00 & .65 & \\
\hline 1. Factor diff. standstill & .90 & 2.60 & 86.74 & .95 & .923 \\
\hline 2. Factor diff. deafened standstill & .90 & .29 & 96.27 & .95 & \\
\hline 3. Factor diff. blinded standstill & .80 & .11 & 100.00 & .90 & \\
\hline
\end{tabular}

Table 3. Pearson's correlation coefficients between variables

\begin{tabular}{|c|c|c|c|c|c|c|c|}
\hline & $\begin{array}{l}\text { Diff. calf } \\
\text { girth }\end{array}$ & $\begin{array}{c}\text { Diff. } \\
\text { upper } \\
\text { arm girth }\end{array}$ & $\begin{array}{l}\text { Diff. } \\
\text { forearm } \\
\text { girth }\end{array}$ & $\begin{array}{l}\text { Diff. thigh } \\
\text { girth }\end{array}$ & $\begin{array}{c}\text { Diff. long } \\
\text { shoulder } \\
\text { height }\end{array}$ & $\begin{array}{l}\text { Diff. arm } \\
\text { lean mass }\end{array}$ & $\begin{array}{c}\text { Diff. leg } \\
\text { lean mass }\end{array}$ \\
\hline Diff. calf girth & 1 & & & & & & \\
\hline Diff. upper arm girth & .02 & 1 & & & & & \\
\hline Diff. forearm girth & .25 & .32 & 1 & & & & \\
\hline Diff. thigh girth & -.24 & -.01 & -.29 & 1 & & & \\
\hline Diff. long shoulder height & .07 & -.34 & .07 & .23 & 1 & & \\
\hline Diff. arm lean mass & .05 & .21 & $.38^{*}$ & -.18 & .09 & 1 & \\
\hline Diff. leg lean mass & $.36^{*}$ & .05 & -.05 & .04 & -.03 & .00 & 1 \\
\hline Factor standstill & -.11 & .25 & -.23 & -.28 & $-.39^{*}$ & -.26 & -.13 \\
\hline
\end{tabular}

Note. Pearson correlation coefficient, $p<.05,{ }^{*}$ significant.

Table 4. Results of regression analysis; dependent variable factor scores for the differences between legs load during standstill balance (simple, deafened and blinded) $(R=.66$, $R^{2}=.43, F=2.60, \operatorname{sig} F=.04, d f 1=7, d f 2=24$ )

\begin{tabular}{lccc}
\hline & Beta & $\mathrm{t}$ & Sig. \\
\hline Diff. calf girth & -.06 & -.34 & .74 \\
Diff. upper arm girth & .39 & 2.14 & $.04^{*}$ \\
Diff. forearm girth & -.36 & -1.90 & .07 \\
Diff. thigh girth & -.41 & -2.30 & $.03^{*}$ \\
Diff. long shoulder height & -.11 & -.61 & .55 \\
Diff. arm lean mass & -.26 & -1.54 & .14 \\
Diff. leg lean mass & -.13 & -.79 & .44 \\
\hline
\end{tabular}

Note. Dependent variable: Factor standstill, $p<.05$, Linear regression; * significant.

\section{Discussion and conclusion}

Main finding is that morphological bilateral asymmetries have an impact on the differences between legs' GRF in standstill balance. Average participants' body height was in accordance with previous findings (Popović, Bjelica, Jakšić, \& Hadžić, 2015) for such a generation of sports students. Paired sample $t$-test (Table 1) showed the differences in the forearm girth and long shoulder height. Because of the significant difference in the long shoulder height, we could conclude that the participants also had asymmetric body posture with a higher right arm and a lower left shoulder's height; the same direction of difference is valid for the forearm girth, where the right side is dominant. The side difference in arm and leg lean mass was not significant. From these results, we can assume that the difference, consequently asymmetry, occurred due to students' fatty tissue.

Those asymmetries are not high and, in terms of normal life, they are not significant; however, they are important from the aspect of leg load. According to the differences in body posture, where the right shoulder side is higher, it is also understandable that the left leg takes more weight. As an average, this is a small amount of weight, but huge differ- 
ences exist among subjects. Although Šarabon et al. (2005) claimed that only those who were doing unilateral sports had significant bilateral asymmetries, the results from our study showed that, in general terms, normal sports activities (recreational level) had also emphasized bilateral asymmetries.

Reliability analysis via factor analysis, where cumulative variance explained by the first factor was from $57.60 \%$ for the blinded standstill, through $70.99 \%$ for the simple standstill to $80.18 \%$ for the deafened standstill, demonstrated that the tests can be defined as reliable. Cronbach's alpha had even higher values (.627 for the blinded, .788 for the simple and .868 for the deafened standstill). Factor analysis of factors scores for each type of the standstill balance measurements extracted the first factor with $86.74 \%$ of variance and Cronbach's alpha of 923. As we did the factor analysis of different standstill balance protocols (the simple standstill with postural control from the somatosensory system, the vestibular system and vision; the deafened standstill and the blinded standstill) and all types of protocols formed one unique factor, where all component matrix coefficients were very high, we can conclude that the somatosensory system was extracted, according to Shumway-Cook and Horak (1986). According to the results, we can confirm that our set of balance tests has adequate validity and reliability and the first factor scores are proper representatives of standstill balance results.

Regression analysis explained $43.1 \%$ of the leg weight differences with morphological characteristics. The significant predictors were the differences in the upper arm and thigh girths. The difference in the upper arm girth was positively related and the difference in the thigh girth was negatively related. A bigger value of the upper arm girth on the left side corresponds to a greater load also on the left leg. Moreover, the bigger the difference between the left and the right thigh, the smaller the difference between legs' load during standstill balance. A higher left thigh girth means the lower load on the left leg. It should be emphasized here that fatty tissue on arms and legs determined girths in our sample.

Such results are in line with Helal and El Fiky (2015) who found out that BMI is in positive correlation with postural instability and with higher values of fatty tissue mass. Alonso et al. (2015) found out that linear regression analysis of postural balance and anthropometrical variables explained much more variance of the medial-lateral postural variability ( $12 \%$ eyes open, $18 \%$ eyes closed) than in the anteroposterior direction ( $6 \%$ eyes open, $0 \%$ eyes closed); in their research body height determined variability of balance, but they did not discuss why the medial-lateral postural variability was predicted better than the anteroposterior one. Greve, Alonso, Bordini, and Camanho (2007) researched correlation between BMI and general postural balance, the anteroposterior stability index and lateral stability index on the dominant and non-dominant leg; they concluded that the comparison of the balance indexes for the dominant and non-dominant sides showed no statistically significant differences. However, they did research load on one isolated leg at a time and with BMI only as an anthropometric parameter, they could not define connections between body asymmetries and postural balance. According to our results, we can state that body symmetry is an important factor of postural balance. The limitations of this study are related to generalization of results; for generalization, further research should include more participants, of both genders and of a wider age span, from the young to the elderly.

The hypothesis was tested that morphological bilateral asymmetry had an impact on the differences in leg pressure in standstill balance. We can conclude that:

- Bilateral differences in morphological characteristics were detected among physically active sports students.

- The significant differences were found in the forearm girth (right side prevailed) and long shoulder height (right side prevailed).

- Morphological bilateral differences significantly determine the differences between the legs in pressure during standstill and explain $43 \%$ of it.

- The best predictors of the differences in leg pressure during standstill are the bilateral differences in the upper arm girth and thigh girth.

- Bigger differences in favour of the left leg are positively related to the differences in the upper arm girth in favour of the left arm and negatively with the differences in the thigh girth in favour of the right leg.

- As the upper arm girth and thigh girth manifested no differences in lean mass, fatty tissue mass induces main relations with the standstill balance differences.

- For practice it is important to balance not only lean mass but fatty tissue mass as well so that there would be no bilateral differences. 


\section{References}

Absaljamov, T.M., Zorin, W.P., \& Koz, J.M. (1976). Kontraktionsgeschwindigkeit von Muskeln und ihre Veränderung im sportlichen Training. Leistungssport, 1(6), 58-61.

Alonso, A.C., Mochizuki, L., Silva Luna, N.M., Ayama, S., Canonica, A.C., \& Greve, J.M. (2015). Relation between the sensory and anthropometric variables in the quiet standing postural control: Is the inverted pendulum important for the static balance control?. BioMed Research International, 2015, article ID 985312. doi: 10.1155/2015/985312

Auerbach, B.M., \& Ruff, C.B. (2006). Limb bone bilateral asymmetry: Variability and commonality among modern humans. Journal of Human Evolution, 50(2), 203-218.

Biospace. (2008). InBody 720 - The precision body composition analyser, User's manual. Retrieved August 8, 2016 from: http://www.bodyanalyse.no/docs/720\%20users\%20manual.pdf

Boyd, L.A., Bontrager, E.L., Mulroy, S.J., \& Perry, J. (1997). The reliability and validity of the novel Pedar system of in-shoe pressure measurement during free ambulation. Gait and Posture, 5(2), 165.

Carter, N., Khan, K., Mallinson, A., Janssen, P., Heinonen, A., \& Petit, M. (2002). Knee extension strength is a significant determinant of static and dynamic balance as well as the quality of life in older community-dwelling women with osteoporosis. Gerontology, 48, 360-368.

Chien, C.W., Lin, J.H., Wang, C.H., Hsueh, I.P., Sheu, C.F., \& Hsieh, C.L. (2007). Developing a short form of the postural assessment scale for people with stroke. Neurorehabilitation and Neural Repair, 21(1), 81-90.

Cronin, J. (2010). Leg asymmetries during running in Australian rules football players with previous hamstring injuries. Journal of Strength and Conditioning Research, 24, 1.

Čuk, I., Pajek, M.B., Jakše, B., Pajek, J., \& Peček, M. (2012b). Morphologic bilateral differences of top level gymnasts. International Journal of Morphology, 30(1), 110-114.

Čuk, I., Pintarič, P., Tušak, M., Belcijan, F., Likovnik, A., \& Bajec, B. (2012a). Sodobno kegljanje. [Contemporary skittle. In Slovenian.] Ljubljana: Kegljaška zveza Slovenije.

Gibson, A.L., Holmes, J.C., Desautels, R.L., Edmonds, L.B., \& Nuudi, L. (2008). Ability of new Octapolar bioimpedance spectroscopy analyzers to predict 4-component.model percentage body fat in Hispanic, black, and white adults. American Journal of Clinical Nutrition, 87(2), 332-338.

Gillespie, L.D., Robertson, M.C., Gillespie, W.J., Sherrington, C., Gates, S., Clemson, L.M., \& Lamb, S.E. (2012). Interventions for preventing falls in older people living in the community. [Online] Cochrane Database of Systematic Reviews, 9(11). doi: 10.1002/14651858. CD007146. pub3

Goulding, A. (2003). Dynamic and static test of balance and postural sway in boys: Effects of previous wrist bone fractures and high adiposity. Gait and Posture, 17(2), 136-142.

Greve, J., Alonso, A., Bordini, A.C.P., \& Camanho, G.L. (2007). Correlation between body mass index and postural balance. Clinics, 62(6), 717-720.

Helal, O.F., \& El Fiky, A.A.R. (2015). Early adult detection is a good protector from balance disturbance in elderly. Journal of Physical Therapy and Health Promotion. 3(4), 47-51.

Horak, F.B. (1987). Clinical measurement of postural control in adults. Physical Therapy, 67(12), 1881-1885.

Krawczyk, B., Skład, M., \& Majle, B. (1995). Body components of male and female athletes representing various sports. Biology of Sport, 12(4), 243-250.

Krawczyk, B., Skład, M., Majle, B., \& Jackiewicz, A. (1998). Lateral asymmetry in upper and lower limb measurements in selected groups of male athletes. Biology of Sport, 15(1), 33-38.

Kruger, A., De Ridder, H., Underhay, C., \& Grobbelaar, H. (2005). Die voorkoms van morfologiese asimmetrie by eliteinternasionale manlike spiesgooiers. [Body morphological asymmetry amongst elite international male javelin throwers. In Afrikaans]. South African Journal for Research in Sport, Physical Education and Recreation, 27(2), 47-55.

Maciaszek, J. (2006). Body composition and motor fitness as determinants of body balance in elderly men. Kinesiologia Slovenica, 12(1), 39-47.

Maffiuletti, N.A., Agosti, F., Proietti, M., Riva, D., Resnik, M., \& Lafortuna, C.L. (2005). Postural instability of extremely obese individuals improves after a body weight reduction program entailing specific balance training. Journal of Endocrinological Investigation, 28(1), 2-7.

Maughan, R.J., Abel, R.W., Watson, J.S., \& Weir, J. (1986). Forearm composition and muscle function in trained and untrained limbs. Clinical Physiology, 6(4), 389-396.

Maureen, A., \& Thornby, P.T. (1995). Balance and falls in the frail older person: A review of the literature. Geriatric Rehabilitation, 11(2), 35-43.

Oliveira, L.F.D., Imbiriba, L.A., \& Garcia, M.A.C. (2000). Índice de estabilidade para avaliação do equilíbrio postural. [Index of stability from evaluation of the postural equilibrium. In Portuguese.] Revista Brasileira Biomecanica, 1(1), 33-38.

Popović, S., Bjelica, D., Jakšić, D., \& Hadžić, V. (2014). Comparative study of anthropometric measurement and body composition between elite soccer and volleyball players. International Journal of Morphology, 32(1), $267-274$.

Shumway-Cook, A., \& Horak, F.B. (1986). Assessing the influence of sensory interaction of balance. Suggestion from the field. Physical Therapy, 66(10), 1548-1550. 
Smith, L.K., Weiss, E.L., \& Lehmkuhl, L.D. (1997). Cinesiologia clínica de Brunnstrom. [Brunnstrom's clinical kinesiology. In Portuguese.] São Paulo: Manole.

Stevens, J.A., Corso, P.S., Finkelstein, E.A., \& Miller, T.R. (2006). The costs of fatal and non-fatal falls among older adults. Injury Prevention, 12(5), 290-295.

Šarabon, N., Košak, R., Fajon, M., \& Drakslar, J. (2005). Nepravilnosti telesne drže - mehanizmi nastanka in predlogi za korektivno vadbo. [Postural deviations: Suggestions for exercise program for posture improvement. In Slovenian.] Šport, 53(1), 35-41.

Talbot, L.A., Musiol, R.J., Witham, E.K., \& Metter, E.J. (2005). Falls in young, middle-aged and older community dwelling adults: Perceived cause, environmental factors and injury. BioMed Central Public Health, $5(1), 86$.

Tyson, S.F., Hanley, M., Chillala, J., Selley, A., \& Tallis, R.C. (2006). Balance disability after stroke. Physical Therapy, 86(1), 30-38.

Zancanaro, C., Milanese, C., Lovato, C., Sandri, M., \& Giachetti, A. (2015). Reliability of three-dimensional photonic scanner anthropometry performed by skilled and naïve operators. International Journal of Ergonomics, 5(1), 1-11.

Winter, D.A. (1995). Human balance and posture control during standing and walking. Gait and Posture, 3(4), $193-214$.

Submitted: April 4, 2017

Accepted: September 26, 2017

Published Online First: December 5, 2018

Ana Kašček Bučinel, Ph.D. student

University of Ljubljana Slovenia, Faculty of Sports

Gortanova 22, 1000 Ljubljana Slovenija

Phone: (01) 5207700

Fax: (01) 5207740

E-mail: ana.kascek@gmail.com 